\title{
Synthesis and Identification of a Novel Peptide, Ac-SDK (Biotin) Proline, That Can Elicit Anti-Fibrosis Effects in Rats Suffering from Silicosis
}

This article was published in the following Dove Press journal: Drug Design, Development and Therapy

\author{
Jin Wang ${ }^{1,2}$ \\ Ye Qian ${ }^{2}$ \\ Xuemin $\mathrm{Gao}^{3}$ \\ $\mathrm{Na} \mathrm{Mao}{ }^{3}$ \\ Yucong Geng ${ }^{4}$ \\ Gaojie Lin $^{3}$ \\ Guibin Zhang ${ }^{2}$ \\ Han $\mathrm{Li}^{3}$ \\ Fang Yang ${ }^{3}$ \\ Hong $\mathrm{Xu}^{3}$ \\ 'Department of Clinical Laboratory, \\ Qingpu Branch of Zhongshan Hospital, \\ Fudan University, Shanghai 20I700, \\ People's Republic of China; ${ }^{2}$ Hebei Key \\ Laboratory for Chronic Diseases, \\ Tangshan Key Laboratory for Preclinical \\ and Basic Research on Chronic Diseases, \\ School of Basic Medical Sciences, North \\ China University of Science and \\ Technology, Tangshan, Hebei 063210, \\ People's Republic of China; ${ }^{3}$ Medical \\ Research Center, International Science \\ and Technology Cooperation Base of \\ Geriatric Medicine, North China \\ University of Science and Technology, \\ Tangshan, Hebei 0632I0, People's \\ Republic of China; ${ }^{4}$ Department of \\ Pathology, Haigang Hospital of \\ Qinhuangdao, Qinhuangdao, Hebei, \\ 066000, People's Republic of China
}

Correspondence: Hong Xu Medical Research Center, International Science and Technology Cooperation Base of Geriatric Medicine, North China University of Science and Technology,

Tangshan, Hebei 0632 I0, People's

Republic of China

Tel +86-3I5-88I6236

Fax +86-3I5-88I6238

Email xuhong@ncst.edu.cn
Background: N-Acetyl-seryl-aspartyl-lysyl-proline (Ac-SDKP) is a short peptide with an anti-silicosis effect. However, the short biological half-life and low plasma concentration of Ac-SDKP hamper discovery of specific targets in organisms and reduce the anti-silicosis effect. A novel peptide, Ac-SDK (biotin) proline, termed "Ac-B", with anti-fibrotic properties was synthesized.

Methods: Ac-B was detected quantitatively by high-performance liquid chromatography. Phagocytosis of Ac-B by the alveolar epithelial cell line A549 was investigated by confocal laser scanning microscopy and flow cytometry. To further elucidate the cellular-uptake mechanism of Ac-B, chemical inhibitors of specific uptake pathways were used. After stimulation with transforming growth factor- $\beta 1$, the effects of Ac-B on expression of the myofibroblast marker vimentin and accumulation of collagen type I in A549 cells were analyzed by Western blotting. Sirius Red staining and immunohistochemical analyses of the effect of Ac-B on expression of $\alpha$-smooth muscle actin (SMA) in a rat model of silicosis were undertaken.

Results: Ac-B had good traceability during the uptake, entry, and distribution in cells. Ac-B treatment prevented an increase in $\alpha$-SMA expression in vivo and in vitro and was superior to that of Ac-SDKP. Caveolae-mediated uptake of Ac-B by A549 cells led to achieving antiepithelial-mesenchymal transformation (EMT) effects.

Conclusion: Ac-B had an anti-fibrotic effect and could be a promising agent for the fibrosis observed in silicosis in the future.

Keywords: Ac-SDKP, biotin, epithelial-mesenchymal transformation, phagocytosis, antifibrotic function

\section{Plain Language Summary}

$\mathrm{N}$-Acetyl-seryl-aspartyl-lysyl-proline (Ac-SDKP) is a short peptide with anti-fibrotic effects. However, the short biological half-life and low plasma concentration of Ac-SDKP make it difficult to find specific targets in organisms and reduce the anti-silicosis fibrosis effect. In our study, a novel visual peptide Ac-SDK (biotin) P [Ac-B] with anti-fibrotic properties was synthesized. It showed good traceability during the processes of cellular uptake, entry, and distribution. Both in vivo and in vitro results indicate that Ac-B has an anti-EMT effect to prevent the progress of silicosis fibrosis. The uptake of Ac-B by endothelial cells occurred via a caveolae-mediated pathway to achieve anti-EMT effects. The good traceability of Ac-B may could ensure its use as a promising agent for anti-silicosis fibrosis therapy and to investigate the distribution, metabolism, and target sites of Ac-B in vivo in animal experiments. 


\section{Introduction}

Silicosis is a severe pneumoconiosis caused by long-term inhalation of large amounts of crystalline silica dust in mining or other dusty occupational environments. ${ }^{1}$ Due to the complex mechanism of its occurrence, curative treatment for silicosis is lacking. ${ }^{2}$

$\mathrm{N}$-Acetyl-seryl-aspartyl-lysyl-proline (Ac-SDKP) is a tetrapeptide with anti-fibrotic effects. It is secreted from bone marrow, and has been found to inhibit proliferation of pluripotent hematopoietic stem cells. ${ }^{3}$ Prolyl oligopeptidase is responsible for the release of Ac-SDKP from its precursor, thymosin- $\beta 4{ }^{4}$ Research involving injury to the heart, ${ }^{5}$ kidney, ${ }^{6}$ lung, ${ }^{7}$ and brain ${ }^{8}$ has shown that Ac-SDKP treatment ameliorates end-organ damage (at least in part) by inhibiting collagen deposition in target organs. Also, Ac-SDKP treatment has been shown to reduce the extent of organ fibrosis caused by pathogenic factors, such as myocardial infarction, ${ }^{9}$ diabetic renal fibrosis, ${ }^{10}$ renal injury, ${ }^{11}$ interstitial lung disease induced by bleomycin, ${ }^{12}$ liver damage induced by bile-duct ligation, ${ }^{13}$ and silicosis, ${ }^{11,14,15}$ in several animal models.

In vitro studies have shown that Ac-SDKP can inhibit the proliferation and collagen synthesis/expression, especially of cardiac fibroblasts, pulmonary fibroblasts, and glomerular mesangial cells. ${ }^{16-18}$ Therefore, Ac-SDKP is a potential drug for the treatment of fibrosis in vivo and in vitro.

Angiotensin-converting enzyme (ACE)-1 is a zinc dipeptidyl carboxypeptidase with two active domains. It plays a key part in regulation of blood pressure and electrolyte homeostasis. Ac-SDKP has a short biological halflife and low plasma concentration. Ac-SDKP is processed exclusively by ACE-1. ${ }^{19}$ Ac-SDKP is a polypeptide drug composed of common amino acids without unusual sidechains, which hampers quantitative detection in vivo. Thus, the clinical application of Ac-SDKP is limited.

Biotin, also named "vitamin H", is a small molecule. It can be coupled to many proteins or peptide macromolecules without obvious influence on its physical, and chemical properties or biological activity. Avidin (molecular weight of its tetrameric form is $66-69 \mathrm{kDa}$ ) can bind to tetramolecular biotin, and the affinity between them is extremely strong and irreversible. The dissociation constant of the avidin-biotin complex is $10-15 \mathrm{~mol} / \mathrm{L}$. The avidin-biotin system plays an important part in the recognition, interaction, purification, detection, fixation, and labeling of molecules. ${ }^{20-23}$
A peptide, Ac-SDK (biotin) proline, which was termed "Ac-B", was prepared by the fusion of biotin and Ac-SDKP via chemical synthesis. The anti-epithelial-mesenchymal transformation (EMT) and anti-fibrotic effects of Ac-B were investigated in vivo and in vitro, respectively. Its good traceability was characterized by exploring its uptake, entry, and distribution in cells. Sustained release of Ac-B in vitro was studied by real-time quantitative detection of Ac-B. The good traceability of Ac-B could aid anti-fibrosis therapy in silicosis, as well as to investigate the distribution, metabolism, and target sites of Ac-B in vivo in animals.

\section{Materials and Methods Chemicals and Reagents}

The high-performance liquid chromatography (HPLC) system was the 1200 series (Agilent Technologies, Santa Clara, CA, USA) with a UV detector and column (XDB-C18, $4.6 \times 15 \mathrm{~cm}$; particle size, $5 \mu \mathrm{m}$; Agilent Technologies). The UV spectrophotometer (UV-2450) was from Shimadzu (Kyoto, Japan). The pH meter (PB10) was from Sartorius (Göttingen, Germany). Water was prepared using the Milli$\mathrm{Q}^{\circledR}$ system (Millipore, Bedford, MA, USA).

Ac-Ser-Asp-Lys (biotin)-Pro (Ac-B; molecular weight 713.79) was synthesized by Shanghai Qiangyao Biotechnology (Shanghai, China).

Acetonitrile and trifluoroacetic acid were of chromatography grade and purchased from Sinopharm Chemical Reagents (Shanghai, China). Phosphate-buffered saline (PBS), Dulbecco's modified Eagle's medium (DMEM), and fetal calf serum were obtained from HyClone (Jülich, Germany). Surfactant protein A (SP-A) was purchased from Beijing Bioss Biotechnology (Beijing, China). Vimentin, $\alpha$-smooth muscle actin (SMA) and transforming growth factor (TGF)- $\beta 1$ were obtained from PeproTech (Rocky Hill, NJ, USA). Collagen type I was purchased from Genetec (Montreal, Canada). Tubulin and glyceraldehyde 3-phosphate dehydrogenase (GAPDH) were obtained from Affinity Biotech (Cincinnati, OH, USA). Dynasore was purchased from Aladdin (Beijing, China). Mycostatin was obtained from Haoranbio (Beijing, China). Streptavidin/ RBITC was purchased from Solarbio (Beijing, China).

\section{Analyses of Ac-B by HPLC}

Ac-B $(10 \mu \mathrm{M})$ was subjected to HPLC using the system and column mentioned above. The column was developed at a flow rate of $1 \mathrm{~mL} / \mathrm{min}$ with a solvent gradient using $0.03 \%$ trifluoroacetic acid in water (solvent A) and 
acetonitrile (solvent B): $20-80 \%$ B over $10 \mathrm{~min}$. The absorbance at $210 \mathrm{~nm}$ was measured using the UV spectrophotometer.

\section{Cell Culture and Experimental Grouping}

The human type II alveolar epithelial A549 cell lines purchased from the Chinese Academy of Sciences cell library (TCHu150, Shanghai, China) were cultured and maintained in RPMI 1640 medium containing 10\% fetal bovine serum in an atmosphere of $5 \% \mathrm{CO}_{2}$ at $37^{\circ} \mathrm{C}$. A549 cells were seeded into six-well plates when confluence reached $50-65 \%\left(\sim 5 \times 10^{4}\right.$ cells $)$. Cells were incubated in medium without serum for $24 \mathrm{~h}$.

Four experimental groups were created: control (cultured in RPMI 1640 without serum for $24 \mathrm{~h}$ ); TGF- $\beta 1$ induction (cultured in serum-free RPMI 1640 and stimulated by TGF$\beta 1(5 \mu \mathrm{g} / \mathrm{L})$ for $24 \mathrm{~h})$; Ac-SDKP drug intervention (TGF- $\beta 1$ + Ac-SDKP; under culture with serum-free RPMI 1640, cells were first induced with Ac-SDKP $\left(10^{-8} \mathrm{~mol} / \mathrm{L}\right)$ and then incubated with TGF- $\beta 1(5 \mu \mathrm{g} / \mathrm{L})$ for $24 \mathrm{~h}$; Ac-B intervention (cells were cultured in RPMI 1640 without serum but with Ac-B $\left(10^{-8} \mathrm{~mol} / \mathrm{L}\right)$ for $1 \mathrm{~h}$ and then incubated with TGF- $\beta 1$ $(5 \mu \mathrm{g} / \mathrm{L})$ for $24 \mathrm{~h}$.

\section{Western Blotting}

After induction, $20 \mu \mathrm{g}$ of protein cell lysate was fractionated by sodium dodecyl sulfate-polyacrylamide gel electrophoresis and transferred to polyvinylidene difluoride (PVDF) membranes. The latter were allowed to react with antibodies against $\alpha$-SMA, collagen $I$, vimentin, GAPDH or tubulin (1:1000 dilution), incubated overnight at $4^{\circ} \mathrm{C}$, and then incubated with anti-goat anti-rabbit immunoglobulin-G (1:5000 dilution) for $30 \mathrm{~min}$ at $37^{\circ} \mathrm{C}$. Electrochemiluminescence reagent was developed for 1 min. Image-Pro Plus (Media Cybernetics, San Diego, CA, USA) was used to analyze protein bands. The ratio of the target protein to the absorbance of the reference protein was taken as the relative expression of the protein.

\section{Cell Phagocytosis}

The efficiency of Ac-B accumulation in A549 cells was analyzed by laser scanning confocal microscope (LSCM) system (Olympus FV1200). Ac-B was configured to $1 \mathrm{mg} /$ $\mathrm{mL}$. After three generations, A549 cells were trypsinized to form a suspension, and $2 \mathrm{~mL}$ of an A549 cell suspension $\left(\sim 2 \times 10^{5}\right.$ cells $)$ was inoculated for LSCM. The final concentration of Ac-B was set to $40 \mu \mathrm{g} / \mathrm{mL}$ per well in a special LSCM culture dish that had been incubated at $37^{\circ} \mathrm{C}$, and three replicates were set. Ac-B uptake by $\mathrm{A} 549$ cells was observed by sequential LSCM at 0, 5, 15, 30, 60 and $120 \mathrm{~min}$. Cell cultures were fixed and labeled with fluorescence-conjugated Streptavidin/RBITC. Treated A549 cells were washed three times with PBS and harvested by trypsinization for quantitative characterization. After centrifugation, cell pellets were washed once and resuspended with PBS buffer. The cellular uptake of AcB was quantitatively determined by flow cytometry. The experiment was carried out in triplicate, and the mean value was calculated.

\section{Mechanisms of Ac-B Uptake by Cells}

The cellular-uptake mechanisms of Ac-B were investigated by blocking the uptake pathway with different treatments. To block energy-dependent endocytosis, cells were preincubated with $\mathrm{NaN}_{3}(10 \mathrm{mM})$ in PBS for $30 \mathrm{~min}$ at $37^{\circ} \mathrm{C}$ to deplete adenosine triphosphate. To block the clathrinmediated pathway by hypertonic treatment, cells were preincubated for $30 \mathrm{~min}$ with sucrose $(0.45 \mathrm{M})$ in PBS at $37^{\circ} \mathrm{C}$. To inhibit clathrin-mediated endocytosis and ultrafast endocytosis at a late stage of vesicle scission, cells were preincubated for $30 \mathrm{~min}$ with dynasore $(80 \mu \mathrm{M})$ in $\mathrm{PBS}$ at $37^{\circ} \mathrm{C}$. Clathrin regenerates synaptic vesicles from endosomes. In addition, cells were pretreated with mycostatin $(5 \mathrm{mg} / \mathrm{mL})$ in PBS for $30 \mathrm{~min}$ to block the caveolae-mediated pathway. Afterwards, all of the cells mentioned above were washed twice with PBS and incubated with Ac-B $(1 \mathrm{mg} / \mathrm{mL})$ in serum-free medium for $2 \mathrm{~h}$ at $37^{\circ} \mathrm{C}$. After washing several times with PBS, treated cells were observed by fluorescence microscopy. Treated cells were washed thrice with PBS and harvested by trypsinization for quantitative characterization. After centrifugation, cell pellets were washed and resuspended in PBS. Cellular uptake of Ac-B was determined quantitatively by flow cytometry. The experiment was carried out in triplicate and the mean value calculated.

\section{Creation of a Silicosis Model in Rats}

Animal-related procedures were undertaken according to protocols approved by the Animal Care and Use Committee of North China University of Science and Technology (2016-0001) in Tangshan, China. Animals received food and water according to guidelines set by the National Institutes of Health (Bethesda, MD, USA).

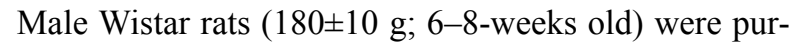
chased from Vital River Laboratory Animal Technology Co. Ltd. (catalog number, SCXY 2009-0004; Beijing, China). 
The silicon dioxide we utilized (purity: 99\%, particle size: $<5 \mu \mathrm{m}$ ) was purchased from Sigma-Aldrich (Saint Louis, MO, USA). Wistar rats were anesthetized with isoflurane. Their tracheae were exposed to a $\mathrm{SiO}_{2}$ solution $(50 \mathrm{mg} / \mathrm{mL}$ per rat) or physiologic $(0.9 \%)$ saline (as vehicle control). Ac-SDKP $(800 \mu \mathrm{g} / \mathrm{kg} \cdot$ day; Bachem, Geneva, Switzerland) or the vehicle control was administered (ip) for 4 weeks. Rats were divided into four groups: control 4 weeks (instilled with $0.9 \%$ saline and then administered $0.9 \%$ saline for 4 weeks); silicosis model 4 weeks (instilled with $\mathrm{SiO}_{2}$ and then administered $0.9 \%$ saline for 4 weeks); Ac-SDKP anti-fibrosis (instilled with $\mathrm{SiO}_{2}$, treated with $0.9 \%$ saline for 4 weeks, and then Ac-SDKP for another 4 weeks); Ac-B anti-fibrosis (instilled with $\mathrm{SiO}_{2}$, treated with $0.9 \%$ saline for 4 weeks, and then Ac-B for another 4 weeks) (Figure 1). Each experimental group comprised eight rats.

\section{Histopathology}

Lung tissues were fixed with $4 \%$ paraformaldehyde and then embedded in paraffin. Transverse sections $(4 \mu \mathrm{m})$ were stained with Sirius Red (Maxin, Fuzhou, China) to observe histopathologic changes and collagen deposition.

\section{Immunohistochemical Analyses}

Immunostaining was carried out on tissue sections. Briefly, $4-\mu \mathrm{m}$ paraffin sections were deparaffinized and rehydrated, followed by conventional preparation of cell slides for immunostaining. Antigen retrieval was done by a highpressure method followed by $15 \mathrm{~min}$ of incubation with $0.03 \% \mathrm{H}_{2} \mathrm{O}_{2}$ to block peroxidase activity. Slides were incubated with $\alpha$-SMA and maintained overnight at $4^{\circ} \mathrm{C}$. Subsequent steps followed the instructions from a one-step polymer-detection system kit (Genetec). Counterstaining was done using hematoxylin. Finally, slides were sealed with neutral balsam. Images were acquired by microscopy (BX53; Olympus, Tokyo, Japan).

\section{Statistical Analyses}

The data were collected and analyzed by SPSS 20.0 (Asia Analytics Formerly SPSS China). The pictures were drawn by Graphpad 8.0. The measurement results were expressed by mean $\pm \mathrm{SD}$ (standard deviation). Differences between two groups were determined by the Student's $t$-test. Differences between two or more groups were analyzed by ANOVA. The value of $p<0.05$ was considered statistically significant.

\section{Results}

\section{Ac-B Absorption}

At a detection wavelength of $210 \mathrm{~nm}$, biotin attachment to Ac-B was detected quantitatively by HPLC (Figure 2). A peak value was not observed for Ac-SDKP (red line in Figure 2), which suggested that Ac-SDKP could not be detected randomly by HPLC at $210 \mathrm{~nm}$. In comparison, the blue line in Figure 2 shows a large peak for Ac-B, which demonstrated that biotin-containing Ac-B could be detected quantitatively by HPLC.

\section{Phagocytic Efficiency of Ac-B in A549 Cells and the Mechanism}

After biotin labeling, Ac-B accumulation in cells could be observed in real-time. Phagocytosis of Ac-B by A549 cells was investigated by LSCM (Figure $3 \mathrm{~A}$ ). At $37^{\circ} \mathrm{C}$, the culture time was set as $0,5,15,30,60$ and $120 \mathrm{~min}$, and the phagocytotic efficiency of Ac-B in A549 cells was $0 \%, 12.6$ $\pm 1.2 \%, 17.7 \pm 0.5 \%, 34.7 \pm 2.1 \%, 65.1 \pm 2.3 \%$ and $96.6 \pm 1.9 \%$, respectively (Figure 3B and C). Ac-B uptake by A549 cells was correlated positively with time on the basis of qualitative

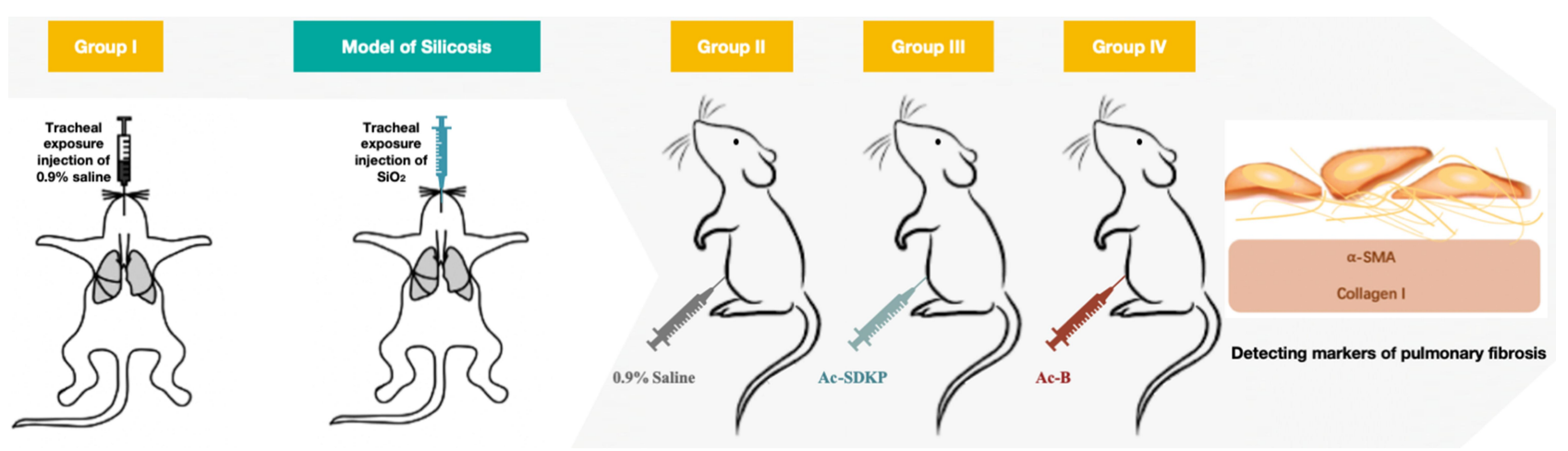

Figure I Silicosis model and treatment scheme. Wistar rats were anesthetized with isoflurane and their tracheae were exposed to a $\mathrm{SiO}{ }_{2}$ solution $(50 \mathrm{mg} / \mathrm{mL}$ per rat) or physiologic $(0.9 \%)$ saline (vehicle control). They were administered via the intraperitoneal route using the treatment scheme as shown with $0.9 \%$ saline, Ac-SDKP, and Ac-B for 4 weeks. Detecting markers of pulmonary fibrosis. 


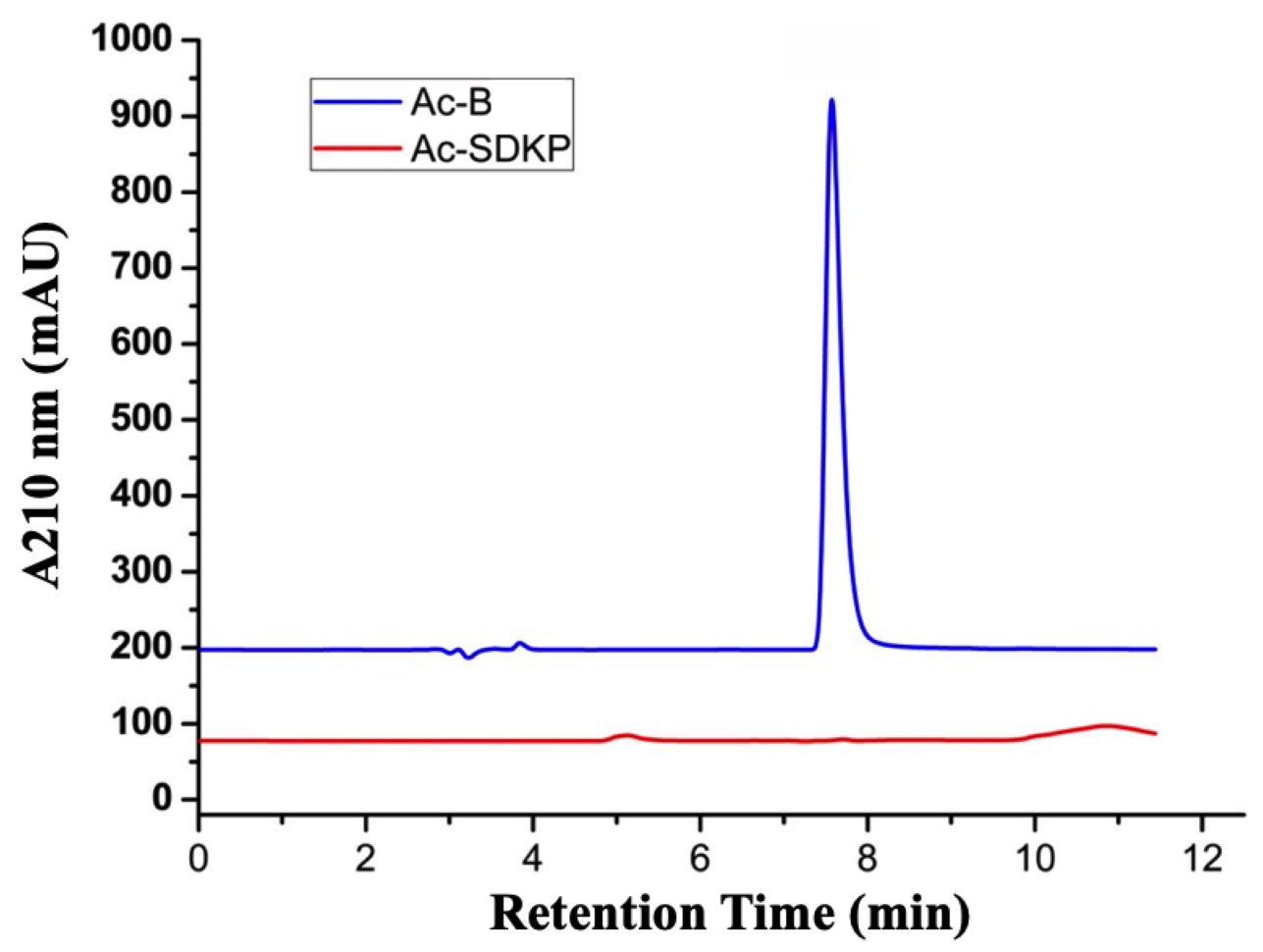

Figure 2 Chromatogram of Ac-B: detection of characteristic peaks of Ac-B by HPLC under absorbance at $210 \mathrm{~nm}$.

and quantitative results. These results reflected the amount of Ac-B taken into the cell after different incubation times.

Chemical inhibitors of specific uptake pathways were used to elucidate further the cellular-uptake mechanism of Ac-B. The presence of $\mathrm{NaN}_{3}$ led to an obvious decrease in intracellular fluorescence intensity compared with that of the control group (Figure 4A), which suggested that Ac-B uptake was dependent upon energy. Cellular uptake of AcB was different when A549 cells were treated individually with corresponding clathrin- and caveolae-mediated endocytosis inhibitors. In particular, mycostatin could reduce Ac-B uptake by cells significantly. These results demonstrated that Ac-B tended to be internalized into cells via the caveolae-mediated pathway. Moreover, flow cytometry was used to quantify the amount of Ac-B uptake by A549 cells. Cellular uptake of Ac-B was reduced markedly $\left(>80 \%\right.$ ) by treatment with $\mathrm{NaN}_{3}$ at $37^{\circ} \mathrm{C}$ (Figures $4 \mathrm{~B}$ and $\mathrm{C}$ ), further demonstrating that internalization was energy-dependent endocytosis. When A549 cells were preincubated with mycostatin $(5 \mathrm{mg} / \mathrm{mL})$, uptake was reduced to $26 \% \pm 2.7 \%$ compared with that of untreated cells. However, pretreatment with sucrose or dynasore did not hinder Ac-B internalization specifically. These results suggested that uptake of Ac-B nanoparticles occurred mainly via the caveolae-mediated pathway.
Effects of Ac-B on Vimentin Expression and Accumulation of Collagen Type $I$ in A549 Cells After Stimulation with TGF- $\beta$ I We demonstrated that Ac-SDKP could suppress myofibroblast differentiation from alveolar epithelial cells (A549). To detect the biological function of Ac-B, we tested the effect of Ac-B treatment on myofibroblast differentiation induced by TGF- $\beta 1$ in A549 cells. Pretreatment with Ac-SDKP/Ac-B for $1 \mathrm{~h}$ before TGF- $\beta$ stimulation could inhibit the decrease in SP-A level (Figure 5B) in epithelial cells significantly. Western blotting indicated increases in expression of markers of interstitial cells: $\alpha$-SMA (Figure 5C), vimentin (Figure 5D), and collagen type I (Figure 5E). Among them, increased expression of vimentin and collagen type I stimulated by TGF- $\beta$ was inhibited markedly by Ac-B pretreatment (Figure 5A).

\section{Effects of Ac-B on $\alpha$-SMA Expression in} a Rat Model of Silicosis

In the silicotic model (4 weeks), cell-fibrous nodules and mass collagen deposition could be observed in silicotic lesions in rats exposed to silica for 4 weeks. The alveolar interstitium was thickened and nodules composed of 
A
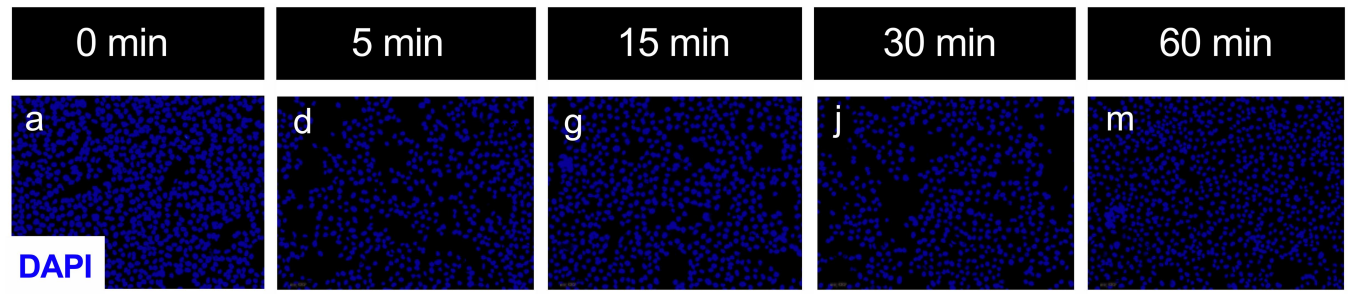

\section{$120 \mathrm{~min}$}
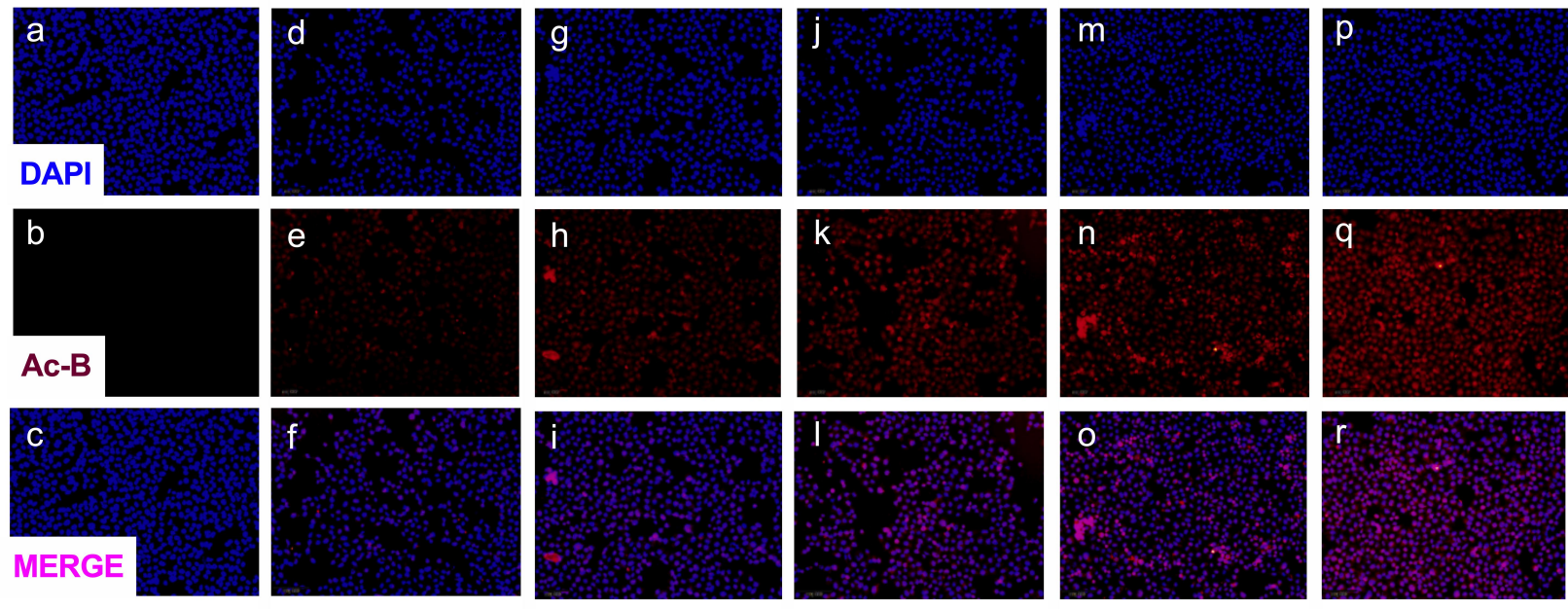

B

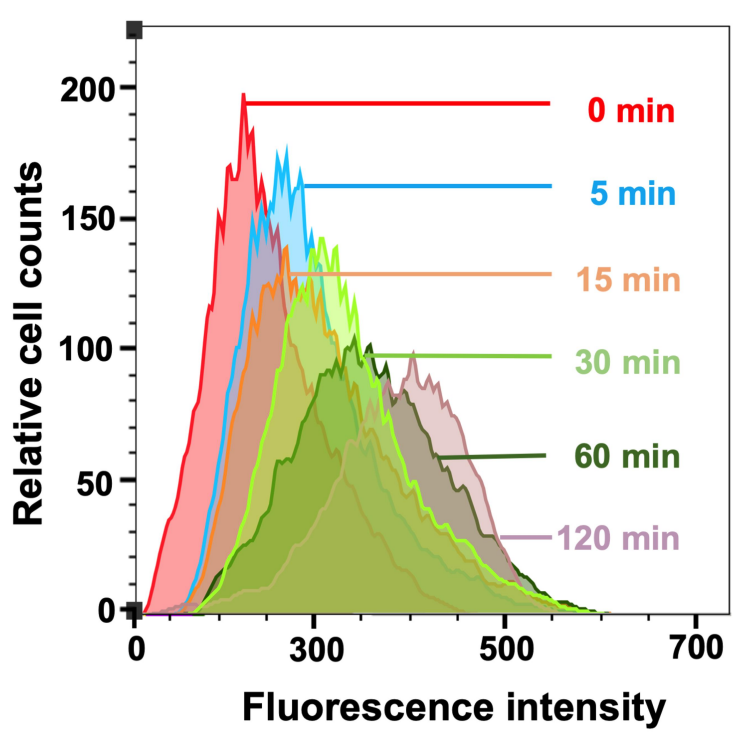

C

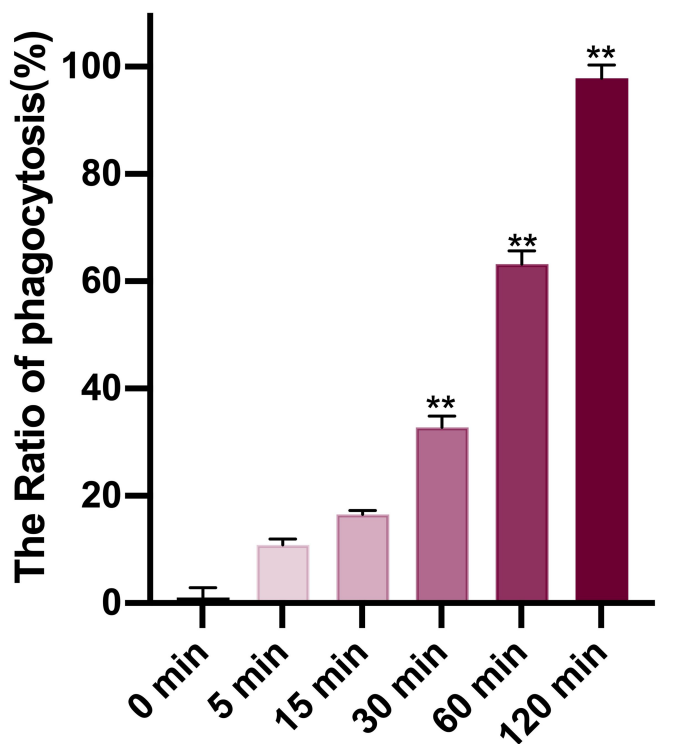

Figure 3 Phagocytosis efficiency of Ac-B by A549 cells. Ac-B ( $40 \mu \mathrm{g} / \mathrm{mL})$ uptake by A549 cells was observed by sequential laser scanning confocal microscope (A) and flow cytometry (B) at 0, 5, 15, 30, 60 and 120 min and three replicates were set. (C) The histograms represent the phagocytosis efficiency of Ac-B by A549 cells. Results are the mean $\pm S D$ of three experiments. $* * P<0.01$.

macrophages and fibroblasts were visible. Compared with the corresponding silicosis control group, Sirius Red staining showed that the numbers of nodules was reduced and the volume of nodules was smaller with less collagen accumulation in Ac-SDKP/Ac-B treatment groups. The therapeutic effect of Ac-B was more efficacious than that of AcSDKP (Figure 6A and C). Furthermore, immunohistochemical staining (Figure 6B) and Western blotting (Figure 6D) showed decreased levels of $\alpha$-SMA in the lungs of rats in the Ac-B group (Figure 6E).

\section{Discussion}

Although the target of the anti-pulmonary-fibrosis effect of Ac-SDKP is not clear, it has been shown to have an anti-EMT effect. EMT is a critical stage during fibrosis development in silicosis, and plays an important part in lung fibrosis. ${ }^{16,17,24,25}$ EMT is the process through which epithelial cells acquire the characteristics of mesenchymal cells following activation by growth factors such as TGF$\beta 1 .^{26,27}$ Growth factors trigger upregulation of genes usually expressed in mesenchymal cells (eg, $\alpha$-SMA, 
A

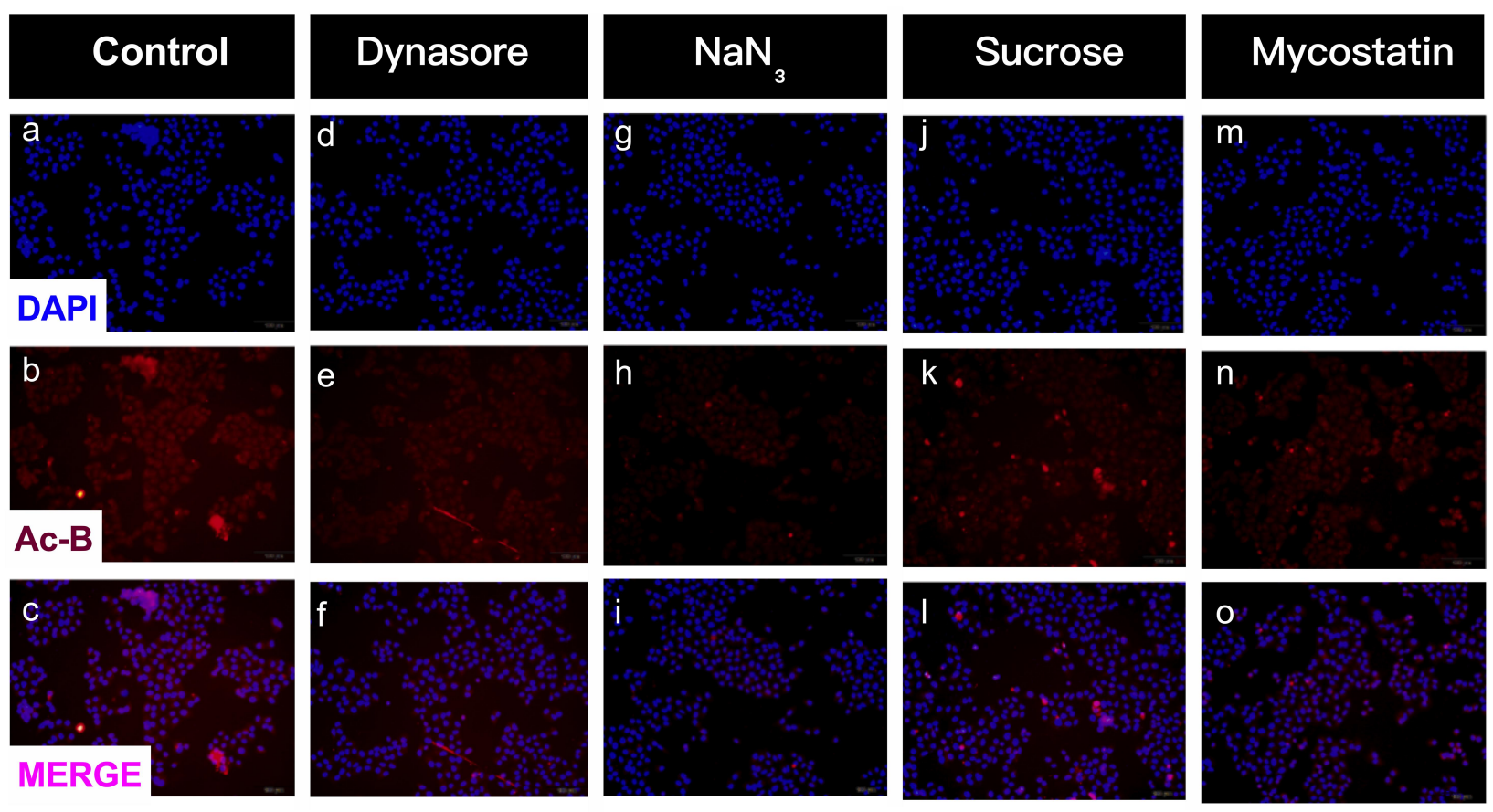

B

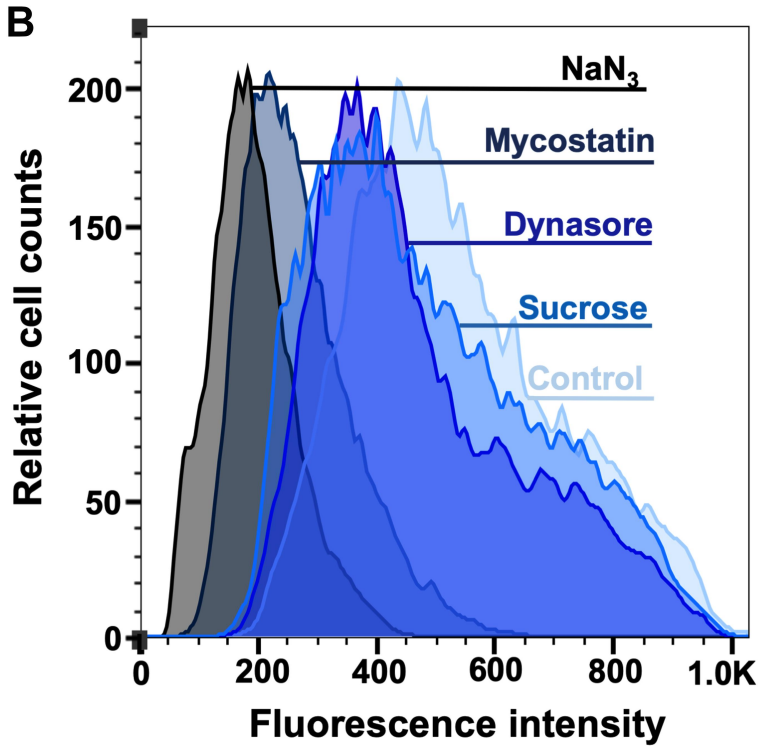

C

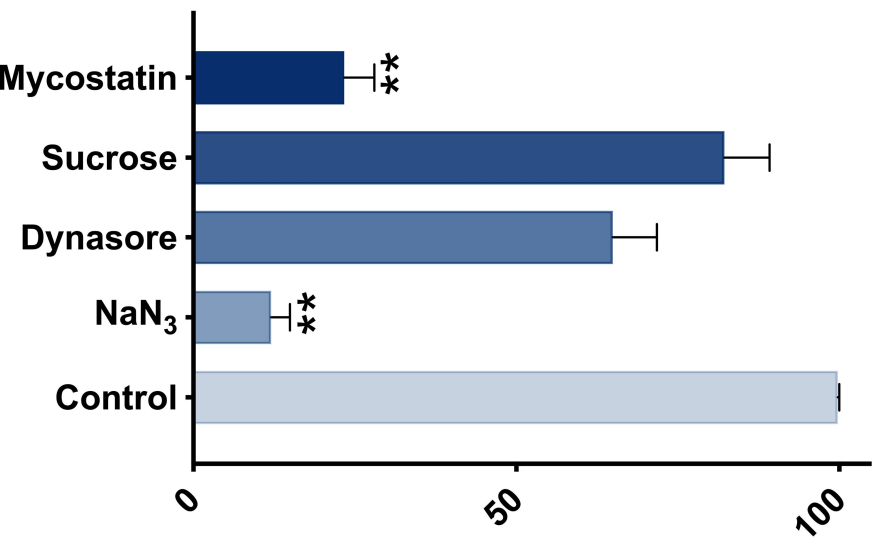

The Ratio of phagocytosis(\%)

Figure 4 Phagocytosis mechanism of $A c-B$ by $A 549$ cells. (A) Fluorescence-microscopy images of $A 549$ cells treated with $A c-B(I \mathrm{mg} / \mathrm{mL})$ for $2 \mathrm{~h}$ at $37^{\circ} \mathrm{C}$ (as a control) and at $37^{\circ} \mathrm{C}$ after pretreatment with $\mathrm{NaN}_{3}(10 \mathrm{mM})$, dynasore $(80 \mu \mathrm{m})$ sucrose $(0.45 \mathrm{M})$ or mycostatin $(5 \mathrm{mg} / \mathrm{mL})$. Red fluorescence shows the location of the Ac-B doped with biotin. Cell nuclei were stained with DAPI (blue). Flow cytometry (B) and the histograms (C) shows the cellular internalization of Ac-B after treatment with different inhibitors. Cellular uptake was normalized against control cells without inhibitor treatment. Results are the mean \pm SD of three experiments. $* * P<0.0$ I.

vimentin) and downregulation of the genes expressed in epithelial cells (eg, E-cadherin, SP-A). ${ }^{28,29}$ Previously, we showed that Ac-SDKP protects the structure and function of type-II alveolar epithelial cells. Thus, Ac-SDKP inhibits the transition of epithelial cell-myofibroblasts via activation of a TGF- $\beta 1 /$ ROCK1 signaling pathway, and this is an anti-fibrotic property of Ac-SDKP. ${ }^{17}$ Recently, we discovered that Ac-SDKP increases expression of $\alpha$ TAT1 and promotes the apoptosis of lung fibroblasts and epithelial cells stimulated with TGF- $\beta 1$ and silica. ${ }^{30}$ Expression of meprin A (a master regulator of AcSDKP), ${ }^{31}$ is diminished by microRNA-155-5p in silicosis and control lung macrophages and fibroblasts upon activation. $^{32}$ 

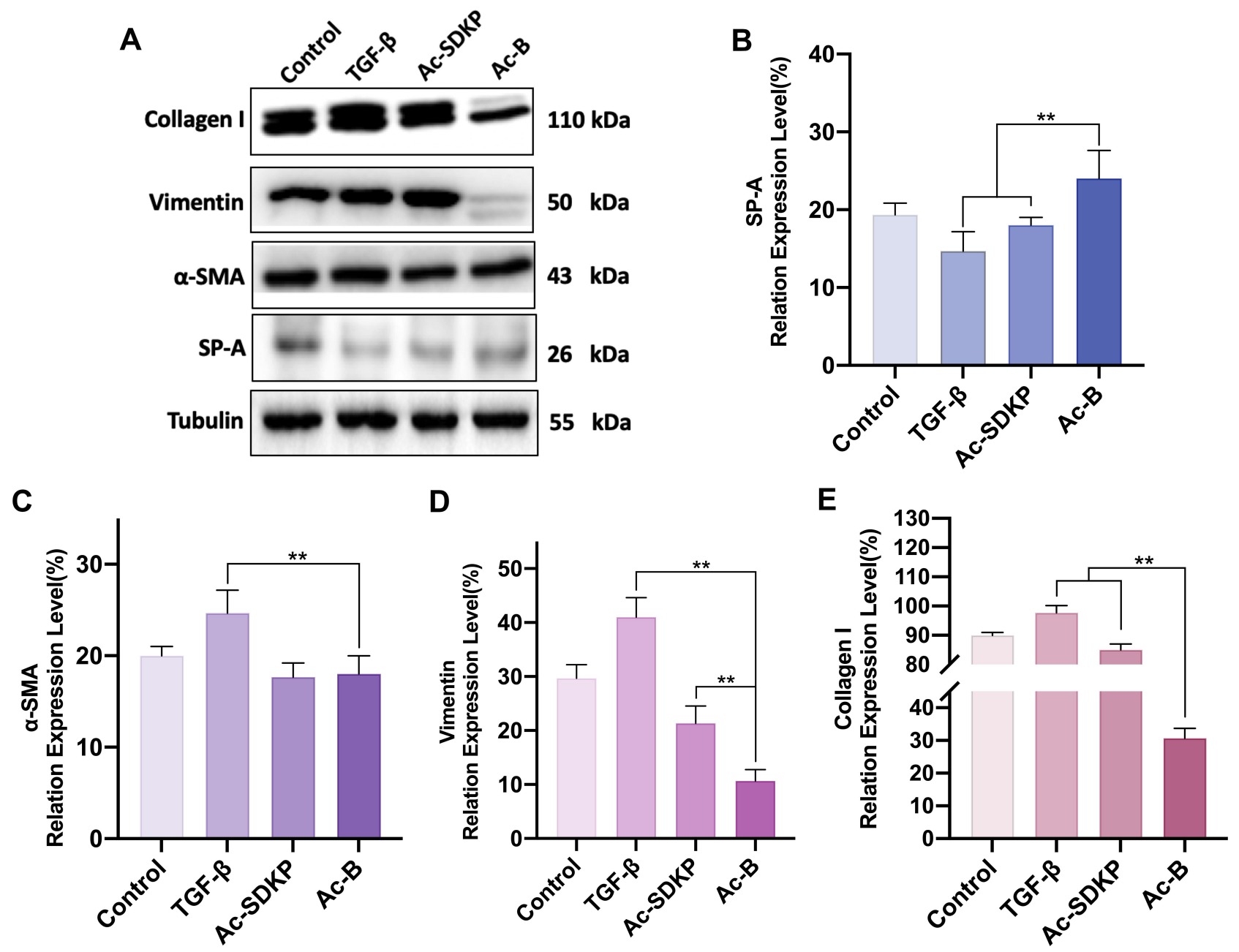

Figure 5 The molecular mechanism by which Ac-B exerts anti-fibrotic effects. (A) Expression of the transcription factors SP-A, vimentin, $\alpha$-SMA, and collagen type I (Western blotting). Densitometric measurement of levels of collagen I type I (B), vimentin (C), $\alpha$-SMA (D) and SP-A (E) normalized to the internal control and expressed as a relative number. $* * \mathrm{P}<0.01$.

Ac-SDKP restricts the fibrosis seen in silicosis by eliciting anti-EMT activity. However, the short biological half-life and low plasma concentration of Ac-SDKP hamper: (i) quantitative detection in vivo; (ii) finding specific targets in organisms. Zhuo et al used ${ }^{125}$ I-labeled 3-(p-hydroxyphenyl)-propionic acid (Hpp)-Aca-SDKP (a biologically active analog of Ac-SDKP) to detect localization of binding sites for Ac-SDKP receptors in rat cardiac fibroblasts ${ }^{33}$ Zhang et al protected Ac-SDKP from physiologic hydroxylation through modification of d-amino acids and enhanced its anti-fibrotic effect upon liver fibrosis. ${ }^{34}$ In the present study, to protect its original anti-fibrotic activity, ${ }^{17}$ biotin was labeled on the $\mathrm{K}$ side-chain of Ac-SDKP to form Ac$\mathrm{B}$ (Figure 7A). Biotin branches cause steric hindrance, which reduces the efficiency of degradation by ACE-1, thereby increasing the Ac-B concentration in plasma. ${ }^{19}$ To detect the biological function of Ac-B, fibrosis models were constructed at cellular and animal levels, respectively. A549 cells were induced by TGF- $\beta$ in vitro to construct a cell model of EMT. Western blotting showed that, compared with control treatment, TGF- $\beta$ treatment decreased expression of the epithelial-cell marker SP-A significantly, and increased expression of the interstitial-cell markers $\alpha$ SMA, vimentin and collagen type I, which suggested that the EMT model had been established. Vimentin controls the transfer of cholesterol from lysosomes to esterification sites while maintaining cytoskeletal stability. It is often used as a marker for mesenchymal cells. Increased expression of vimentin indicates that EMT has been accelerated. We found that Ac-B could inhibit EMT effectively, which suggested that Ac-B could also maintain/preserve epithelial cells and suppress mesenchymal cells during silicosis. Western blotting indicated that the anti-EMT effect of Ac-B was better than that observed in Ac-SDKP groups. 
A

Collagen
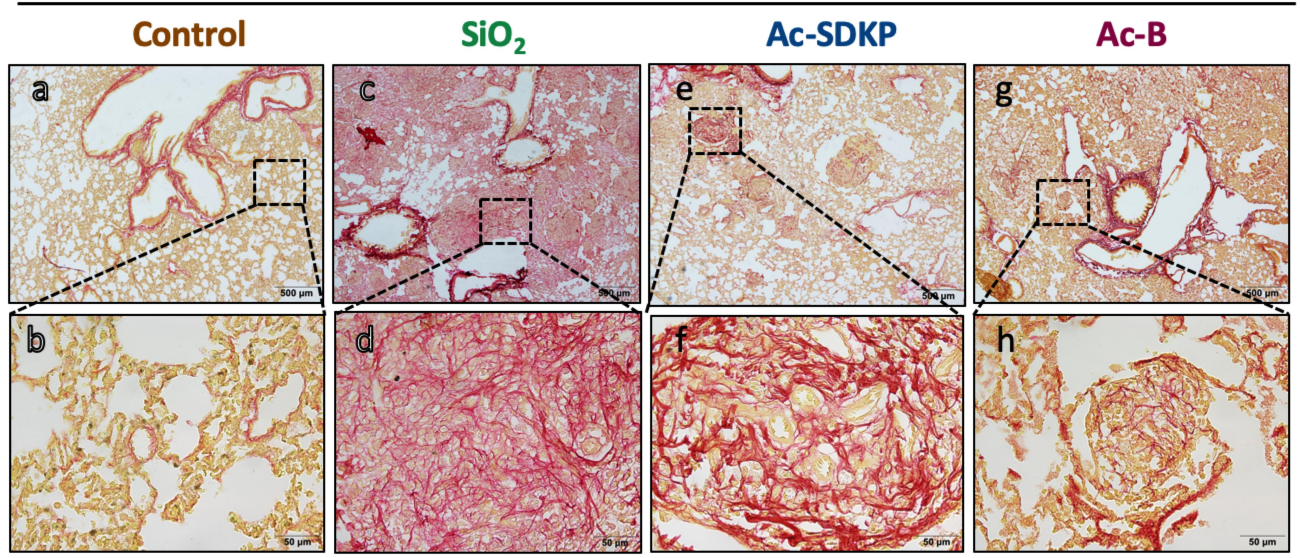

B

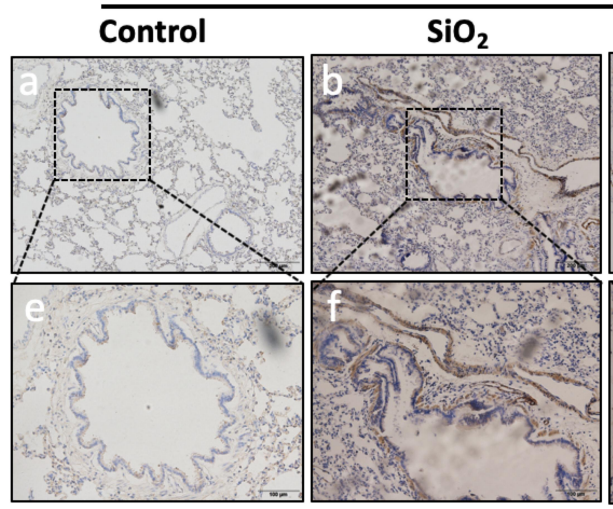

$\alpha$-SMA

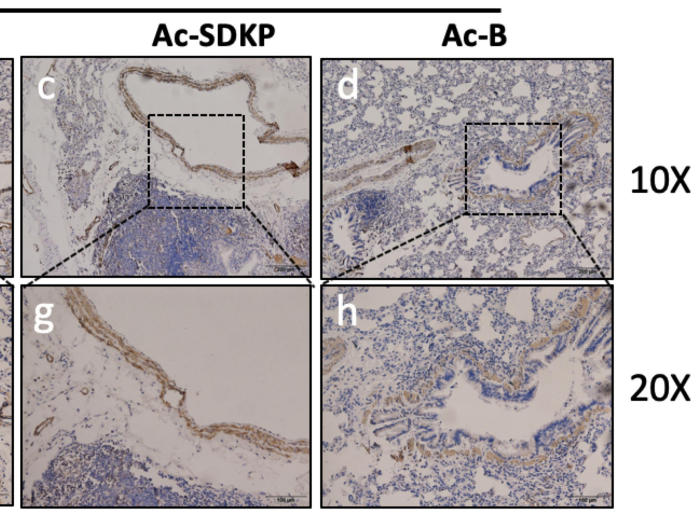

C

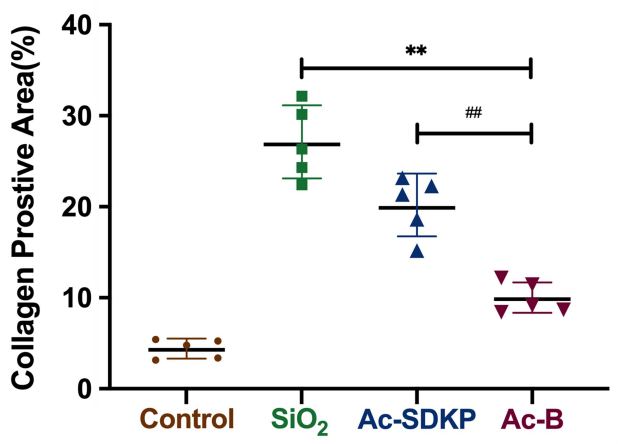

D

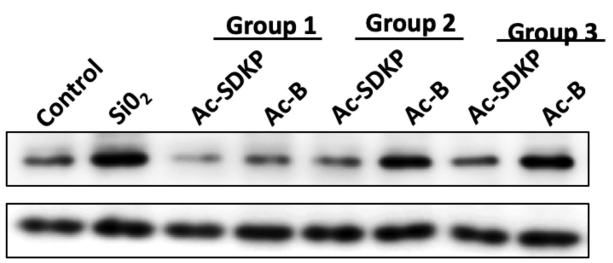

E

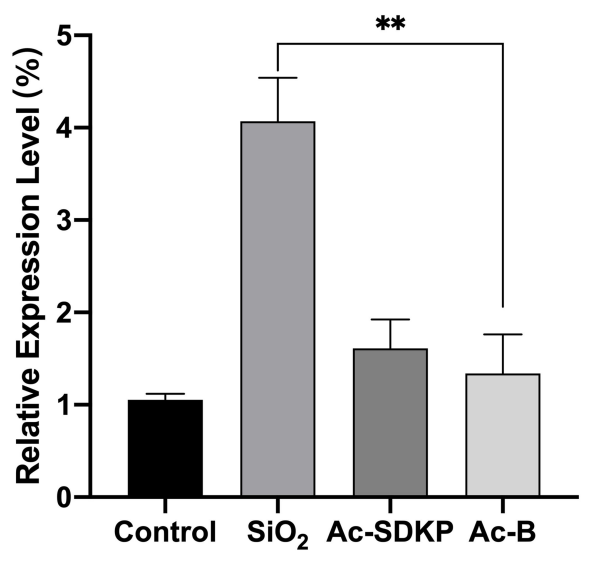

GAPDH

Figure 6 Observation of pathologic changes in a rat model of silicosis. Effects of Ac-B on the morphologic changes of lung tissue in a rat model of silicosis (A and C). Sirius Red was used to stain the lung tissues of rats from different groups, as indicated. Scale bar: $500 \mu \mathrm{m}$ and $50 \mu \mathrm{m}$. The anti-fibrosis efficacy of Ac-SDKP and Ac-B on silicosis in rats. (B) Mesenchymal-cell marker ( $\alpha$-SMA) immunostaining (positive expression = brown). (D) Western blotting for $\alpha$-SMA protein from treatment or non-treatment by Ac-SDKP/Ac-B. Control: control 4 weeks (instilled with $0.9 \%$ saline and then administered $0.9 \%$ saline for 4 weeks); $\mathrm{SiO}_{2}$ : silicosis model 4 weeks (instilled with $\mathrm{SiO}_{2}$ and then administered $0.9 \%$ saline for 4 weeks); therapy group: Ac-SDKP and Ac-B anti-fibrosis respectively. Ac-SDKP anti-fibrosis (instilled with SiO ${ }_{2}$, treated with $0.9 \%$ saline for 4 weeks, and then Ac-SDKP for another 4 weeks); Ac-B anti-fibrosis (instilled with $\mathrm{SiO}_{2}$, treated with $0.9 \%$ saline for 4 weeks, and then Ac-B for another 4 weeks). Each experimental group comprised eight rats. Repeat three control groups. (E) Densitometric measurement of $\alpha$-SMA protein level normalized to that of the internal control, respectively, and expressed as a relative number. Data are the mean \pm SD ( $n=5$ per group). Statistical analyses were undertaken using one-way ANOVA. **P $<0.00$ I vs silicosis 4 weeks; \#P $<0.00$ I vs Ac-SDKP. (For interpretation of the references to color in this figure legend, the reader is referred to the online version of this article.). 
A

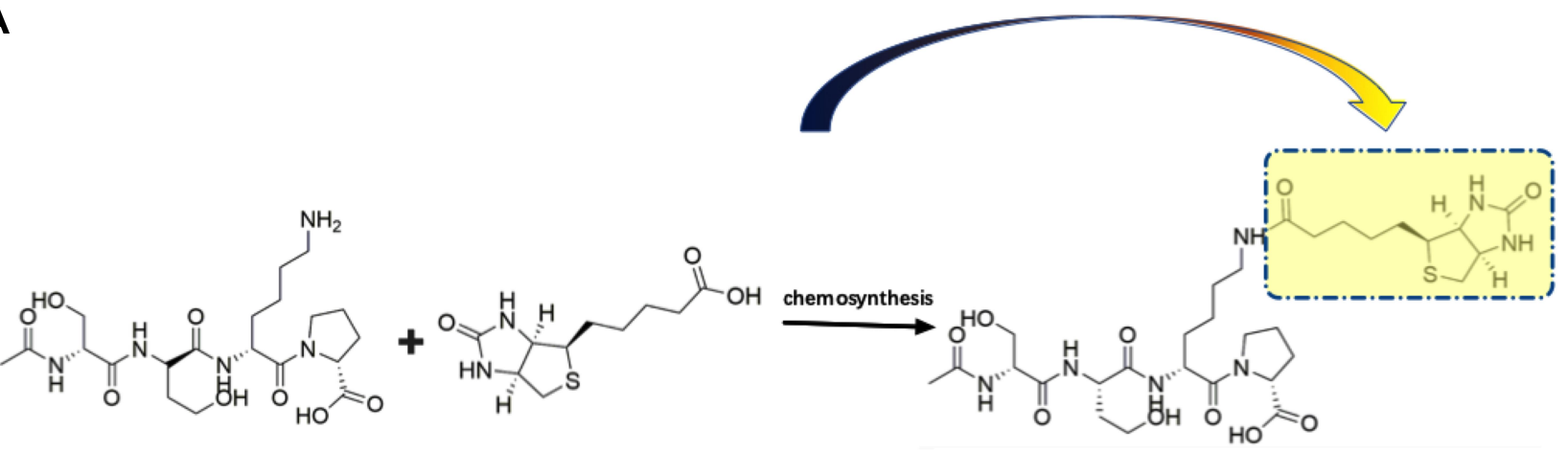

Ac-SDKP

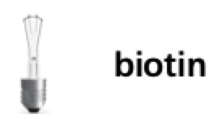

Ac-SDK(biotin)P

B

\section{Epithelial phenotypes}

\section{Mesenchymal phenotypes}

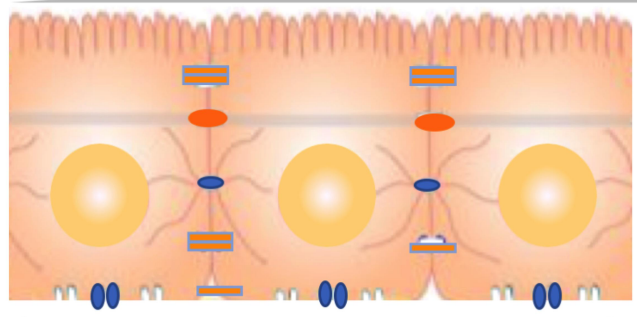

E-cadherin

Cytokeratin

$\infty$ Surfactant proteins (SP-A)

\section{Caveolae-Mediated Pathway}
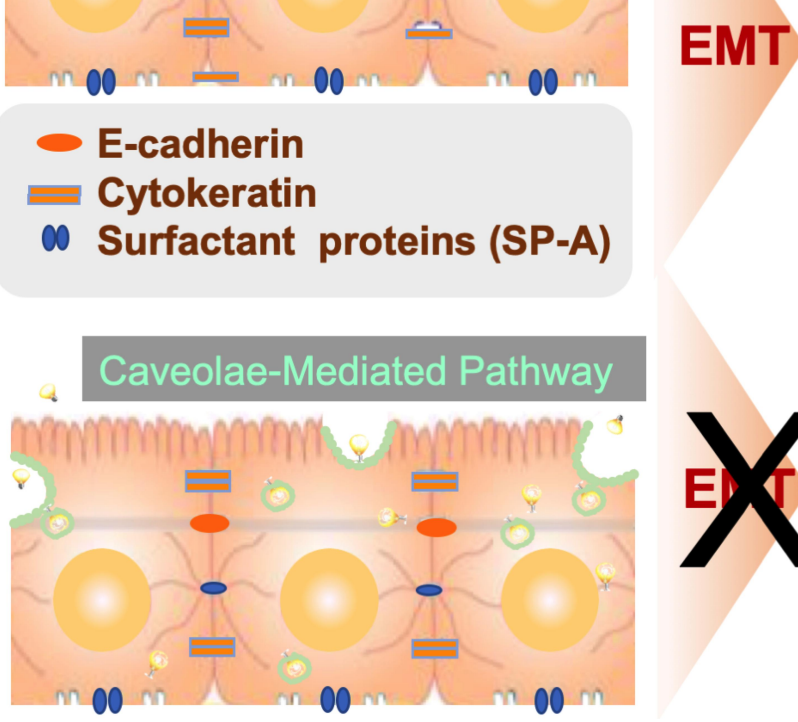

17

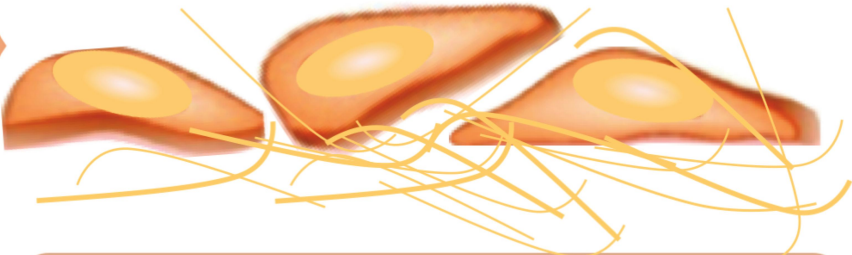

$\alpha-S M A$

Collagen I

Vimentin

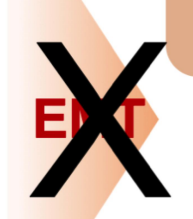

Ac-B

Figure 7 (A) Chemical composition of Ac-B. The K side-chain of Ac-SDKP was modified with biotin. Biotin was labeled on the K side-chain of Ac-SDKP to form Ac-B. When biotin is combined with Streptavidin/RBITC, Ac-B is visualized. (B) Mechanism by which Ac-B inhibits fibrosis in silicosis through anti-EMT activity (schematic). Ac-B achieves an anti-EMT effect after entering into endothelial cells via caveolae-mediated endocytosis.

These results showed that this complex had excellent action against EMT (Figure 5) and good traceability, which allowed real-time quantitative detection of Ac-SDKP during uptake (Figure 3), entry, and distribution in cells. At 4 weeks in the silicosis model in rats, Ac-B restored the consequences of $\mathrm{SiO}_{2}$-mediated fibrosis caused by silicosis
(Figure 6). Ac-B was able to enter into endothelial cells via caveolae-mediated, but not clathrin-mediated, endocytosis and achieved an anti-EMT effect to stop fibrosis in silicosis (Figure 4; Figure7B). In subsequent experiments, we explored the target site of the anti-pulmonary fibrosis effects of Ac-B in a rat model of silicosis. Fibrosis 
associated with inhalation of silica particles is deeply related to inflammasomes and cytokines released. We will further study the effect of Ac-B on them. Explore the role of Ac-B in the treatment of other fibrotic diseases in further research.

\section{Conclusions}

Ac-B, an anti-fibrotic peptide with good traceability, was prepared via attachment of biotin to Ac-SDKP. The mechanism for the phagocytosis of Ac-B by cells was elucidated. Cell experiments and animal experiments showed that Ac-B had an anti-EMT effect to prevent the progress of fibrosis in silicosis. Ac-B uptake by endothelial cells occurred via a caveolae-mediated pathway to achieve anti-EMT effects. The good traceability of Ac-B may enable its use as an agent for anti-silicosis therapy, as well as to investigate the distribution, metabolism and target sites of Ac-B in vivo in animals.

\section{Data Sharing Statement}

The data used to support the findings of this study are available from the corresponding author upon request.

\section{Author Contributions}

All authors made substantial contributions to conception and design, acquisition of data, or analysis and interpretation of data; took part in drafting the article or revising it critically for important intellectual content; agreed to submit to the current journal; gave final approval of the version to be published; and agree to be accountable for all aspects of the work.

\section{Funding}

This work was supported financially by the National Natural Science Foundation of China (31800715), Natural Science Foundation of Hebei Province (H2017209190), Department of Science and Technology of Hebei Province (16272707), Health and Family Planning Commission of Hebei Province (20170888) and the North China University of Science and Technology Outstanding Youth Science Foundation.

\section{Disclosure}

The authors report no conflicts of interest in this work.

\section{References}

1. Franklin BS, Mangan MS, Latz E. Crystal formation in inflammation. Annu Rev Immunol. 2016;34:173-202. doi:10.1146/annurev-immunol $-041015-055539$
2. Leung CC, Yu IT, Chen W. Silicosis. Lancet. 2012;379 (9830):2008-2018. doi:10.1016/S0140-6736(12)60235-9

3. Thierry J, Grillon C, Gaudron S, Potier P, Riches A, WdzieczakBakala J. Synthesis and biological evaluation of analogues of the tetrapeptide N-Acetyl-Ser-Asp-Lys-Pro (AcSDKP), an inhibitor of primitive haematopoietic cell proliferation. J Pept Sci. 2001;7 (5):284-293. doi:10.1002/psc.322

4. Cavasin MA, Liao TD, Yang XP, Yang JJ, Carretero OA. Decreased endogenous levels of Ac-SDKP promote organ fibrosis. Hypertension. 2007;50(1):130-136.

5. Sharma UC, Sonkawade SD, Spernyak JA, et al. A small peptide Ac-SDKP inhibits radiation-induced cardiomyopathy. Circ Heart Fail. 2018;11(8):e004867. doi:10.1161/CIRCHEARTFAILURE. 117.004867

6. Romero CA, Kumar N, Nakagawa P, et al. Renal release of N-acetylseryl-aspartyl-lysyl-proline is part of an antifibrotic peptidergic system in the kidney. Am J Physiol Renal Physiol. 2019;316(1):F195F203. doi:10.1152/ajprenal.00270.2018

7. Zhang B, Xu H, Zhang Y, et al. Targeting the RAS axis alleviates silicotic fibrosis and Ang II-induced myofibroblast differentiation via inhibition of the hedgehog signaling pathway. Toxicol Lett. 2019;313:30-41. doi:10.1016/j.toxlet.2019.05.023

8. Pejman S, Kamarehei M, Riazi G, Pooyan S, Balalaie S. Ac-SDKP ameliorates the progression of experimental autoimmune encephalomyelitis via inhibition of ER stress and oxidative stress in the hippocampus of C57BL/6 mice. Brain Res Bull. 2020;154:21-31. doi:10.1016/j.brainresbull.2019.09.014

9. Ntsekhe M, Matthews K, Wolske J, et al. Scientific letter: ac-SDKP ( $\mathrm{N}$-acetyl-seryl-aspartyl-lysyl-proline) and galectin-3 levels in tuberculous pericardial effusion: implications for pathogenesis and prevention of pericardial constriction. Heart. 2012;98(17):1326-1328. doi:10.1136/heartjnl-2012-302196

10. Yang F, Yang XP, Liu YH, et al. Ac-SDKP reverses inflammation and fibrosis in rats with heart failure after myocardial infarction. Hypertension. 2004;43(2):229-236. doi:10.1161/01.HYP.0000107777. 91185.89

11. Zhang L, Xu LM, Chen YW, et al. Antifibrotic effect of N-acetylseryl-aspartyl-lysyl-proline on bile duct ligation induced liver fibrosis in rats. World J Gastroenterol. 2012;18(37):5283-5288.

12. Srivastava SP, Shi S, Kanasaki M, et al. Effect of antifibrotic MicroRNAs crosstalk on the action of N-acetyl-seryl-aspartyl-lysylproline in diabetes-related kidney fibrosis. Sci Rep. 2016;6:29884. doi:10.1038/srep29884

13. Worou ME, Liao TD, D'Ambrosio M, et al. Renal protective effect of N-acetyl-seryl-aspartyl-lysyl-proline in dahl salt-sensitive rats. Hypertension. 2015;66(4):816-822. doi:10.11 61/HYPERTENSIONAHA.115.05970

14. Zhang L, Xu D, Li Q, et al. N-acetyl-seryl-aspartyl-lysyl-proline (Ac-SDKP) attenuates silicotic fibrosis by suppressing apoptosis of alveolar type II epithelial cells via mediation of endoplasmic reticulum stress. Toxicol Appl Pharmacol. 2018;350:1-10. doi:10.1016/j. taap.2018.04.025

15. Xu H, Yang F, Sun Y, et al. A new antifibrotic target of Ac-SDKP: inhibition of myofibroblast differentiation in rat lung with silicosis. PLoS One. 2012;7(7):e40301. doi:10.1371/journal.pone.0040301

16. Deng $\mathrm{H}$, Yang $\mathrm{F}$, $\mathrm{Xu} \mathrm{H}$, et al. Ac-SDKP suppresses epithelial-mesenchymal transition in A549 cells via HSP27 signaling. Exp Mol Pathol. 2014;97(1):176-183. doi:10.1016/j.yexmp.2014.07.003

17. Deng $\mathrm{H}, \mathrm{Xu} \mathrm{H}$, Zhang X, et al. Protective effect of Ac-SDKP on alveolar epithelial cells through inhibition of EMT via TGF-beta1/ ROCK1 pathway in silicosis in rat. Toxicol Appl Pharmacol. 2016;294:1-10. doi:10.1016/j.taap.2016.01.010

18. Ma X, Yuan Y, Zhang Z, Zhang Y, Li M. An analog of Ac-SDKP improves heart functions after myocardial infarction by suppressing alternative activation (M2) of macrophages. Int J Cardiol. 2014;175 (2):376-378. doi:10.1016/j.ijcard.2014.05.016 
19. Masuyer G, Douglas RG, Sturrock ED, Acharya KR. Structural basis of Ac-SDKP hydrolysis by angiotensin-I converting enzyme. Sci Rep. 2015;5:13742. doi:10.1038/srep13742

20. Fujii S, Mori S, Kagechika H, Mendoza Parra MA, Gronemeyer H. Development of biotin-retinoid conjugates as chemical probes for analysis of retinoid function. Bioorg Med Chem Lett. 2018;28 (14):2442-2445. doi:10.1016/j.bmcl.2018.06.011

21. Lin WZ, Chen YH, Liang CK, Liu CC, Hou SY. A competitive immunoassay for biotin detection using magnetic beads and gold nanoparticle probes. Food Chem. 2019;271:440-444. doi:10.1016/j. foodchem.2018.07.152

22. Ohmuro-Matsuyama Y, Yamashita T, Gomi K, Yamaji H, Ueda H. Evaluation of protein-ligand interactions using the luminescent interaction assay FlimPIA with streptavidin-biotin linkage. Anal Biochem. 2018;563:61-66. doi:10.1016/j.ab.2018.10.010

23. Kojima N, Suda T, Kurinomaru T, Kurita R. Immobilization of DNA with nitrogen mustard-biotin conjugate for global epigenetic analysis. Anal Chim Acta. 2018;1043:107-114. doi:10.1016/j.aca.2018.09.008

24. Qian W, Cai X, Qian Q Sirt1 antisense long non-coding RNA attenuates pulmonary fibrosis through sirt1-mediated epithelial-mesenchymal transition. Aging (Albany NY). 2020;12(5):4322-4336. doi:10.18632/ aging. 102882

25. Zuo H, Trombetta-Lima M, Heijink IH, et al. A-kinase anchoring proteins diminish TGF-beta1/cigarette smoke-induced epithelial-to-mesenchymal transition. Cells. 2020;9(2):356. doi:10.3390/cells9020356

26. Zhang K, Fan C, Cai D, et al. Contribution of TGF-beta-mediated NLRP3-HMGB1 activation to tubulointerstitial fibrosis in rat with angiotensin ii-induced chronic kidney disease. Front Cell Dev Biol. 2020;8:1. doi:10.3389/fcell.2020.00001

27. Song L, Chen TY, Zhao XJ, et al. Pterostilbene prevents hepatocyte epithelial-mesenchymal transition in fructose-induced liver fibrosis through suppressing miR-34a/Sirt1/p53 and TGF-beta1/Smads signalling. $B r J$ Pharmacol. 2019;176(11):1619-1634. doi:10.1111/ bph.14573
28. Jung J, Lee YJ, Choi YH, Park EM, Kim HS, Kang JL. Gas6 prevents epithelial-mesenchymal transition in alveolar epithelial cells via production of PGE2, PGD2 and their receptors. Cells. 2019;8(7):643. doi:10.3390/cells8070643

29. Liu P, Zhang B, Chen Z, et al. m(6)A-induced IncRNA MALAT1 aggravates renal fibrogenesis in obstructive nephropathy through the miR-145/FAK pathway. Aging (Albany NY). 2020;12(6):5280-5299. doi:10.18632/aging. 102950

30. Shifeng L, Hong X, Xue Y, et al. Ac-SDKP increases alpha-TAT 1 and promotes the apoptosis in lung fibroblasts and epithelial cells double-stimulated with TGF-betal and silica. Toxicol Appl Pharmacol. 2019;369:17-29. doi:10.1016/j.taap.2019.02.015

31. Kumar N, Nakagawa P, Janic B, et al. The anti-inflammatory peptide Ac-SDKP is released from thymosin-beta4 by renal meprin-alpha and prolyl oligopeptidase. Am J Physiol Renal Physiol. 2016;310(10): F1026-F1034. doi:10.1152/ajprenal.00562.2015

32. Chen Y, Xu D, Yao J, et al. Inhibition of miR-155-5p exerts anti-fibrotic effects in silicotic mice by regulating meprin alpha. Mol Ther Nucleic Acids. 2020;19:350-360. doi:10.1016/j.omtn.2019.11.018

33. Zhuo JL, Carretero OA, Peng H, et al. Characterization and localization of Ac-SDKP receptor binding sites using ${ }^{125}$ I-labeled Hpp-AcaSDKP in rat cardiac fibroblasts. Am J Physiol Heart Circ Physiol. 2007;292(2):H984-H993. doi:10.1152/ajpheart.00776.2006

34. Zhang X, Zhou J, Zhu Y, et al. d-amino acid modification protects $\mathrm{N}$-Acetyl-seryl-aspartyl-lysyl-proline from physiological hydroxylation and increases its antifibrotic effects on hepatic fibrosis. IUBMB Life. 2019;71(9):1302-1312. doi:10.1002/iub.2037

\section{Publish your work in this journal}

Drug Design, Development and Therapy is an international, peerreviewed open-access journal that spans the spectrum of drug design and development through to clinical applications. Clinical outcomes, patient safety, and programs for the development and effective, safe, and sustained use of medicines are a feature of the journal, which has also been accepted for indexing on PubMed Central. The manuscript management system is completely online and includes a very quick and fair peer-review system, which is all easy to use. Visit http://www. dovepress.com/testimonials.php to read real quotes from published authors. 